\title{
Submental Endotracheal Intubation: A Useful Alternative
}

\author{
Kanwaldeep Singh Soodan ${ }^{1 *}$ and Pratiksha Priyadarshni ${ }^{2}$ \\ ${ }^{1}$ Department of Oral \& Maxillofacial Surgery, MM College of Dental Sciences and Research, India \\ ${ }^{2}$ Dental Surgeon, India
}

Submission: January 29, 2018; Published: February 21, 2018

*Corresponding author: Kanwaldeep Singh Soodan, Department of Oral \& Maxillofacial Surgery, MM College of Dental Sciences and Research, Mullana, India, Email: dr.kanwal@rediffmail.com

\begin{abstract}
Submental endotracheal intubation is a simple, useful and safe technique in maxillofacial trauma when oral and nasal endotracheal intubation cannot be performed. It prevents need for tracheostomy and its consequent morbidity. Airway management in patients with panfacial trauma is challenging due to disruption of components of upper airway. Most patients have associated nasal fractures where use of nasal route of intubation contra-indicated. Intermittent intra-operative dental occlusion is needed to check alignment of the fracture fragments, which contraindicates the use of orotracheal intubation. The anesthesiologist has to share the airway with the surgeons. Submental intubation provides intra-operative airway control, avoids use of oral and nasal route, with minimal complications. Submental intubation allows intra-operative dental occlusion and is an acceptable option, especially when long-term postoperative ventilation is not planned. This technique has minimal complications and has better patients and surgeons acceptability.
\end{abstract}

Keywords: Intubation; Panfacial trauma; Contraindication; Complication

\section{Introduction}

Francisco Hernandez Altemir in 1986 first reported Submental intubation. According to him, it's a procedure that avoids tracheotomy and allow for the concomitant restoration of occlusion and reduction of facial fractures in patients ineligible for nasotracheal intubation [1]. This procedure consists of exteriorizing an oral endotracheal tube through the floor of the mouth and submental triangle. The surgical procedure involves a $2 \mathrm{~cm}$ incision in the Submental, paramedial region extending cephalad until the lingual mucosa was tented with a hemostat after which another $2 \mathrm{~cm}$ incision parallel to the mandible is made in the lingual gingiva. The breathing circuit is briefly disconnected as the tube is externalized through the Submental region and reconnected to the circuit and secured to the patient. Submental intubation is a surgical adjunct in facial trauma, pathology and elective facial surgery.

Oral intubation interferes with maxillomandibular reduction. In situations where maxillomandibular fixation is required and nasoendotracheal intubation is contraindicated, cricothyrotomy or tracheostomy has been the traditional method of airway control [2]. Submental intubation technique consists of passing the tube through the anterior floor of mouth, allowing free intra-operative access to oral cavity and nasal pyramid without endangering patients with skull base trauma. Submental intubation can be used when short term postoperative control of airway is desirable with the presence of undisturbed access to oral as well as nasal airways and a good dental occlusion.

\section{Case Report}

A 35 year old male patient with $70 \mathrm{~kg}$ weight met with a road traffic accident and was admitted to hospital. On admission patient was conscious with a Glasgow coma score of 15 . On examination, there was facial swelling, laceration at Naso-orbitoethmoid region and epistaxis was present. There was tenderness at zygomatic buttress region and mouth opening was restricted. Radiological examination revealed Nasal bone fracture with presence of high Lefort I fracture on the right side (Figure 1).

The patient was scheduled for surgical correction of multiple facial fractures. Nasal endotracheal intubation was contraindicated in the presence of nasal bone fracture. Oral endotracheal intubation was not possible because the surgical procedure involved intraoperative intermaxillary fixation to 
obtain occlusion. In order to avoid tracheostomy, submental endotracheal intubation was planned. Patient was kept fasting for 8 hours preoperatively. He was premedicated in preoperative room and then in operation theatre was preoxygenated with $100 \%$ oxygen for three minutes. A $2 \mathrm{~cm}$ incision was made in left submental region parallel and medial to inferior border of mandible by the surgeon (Figure 2).
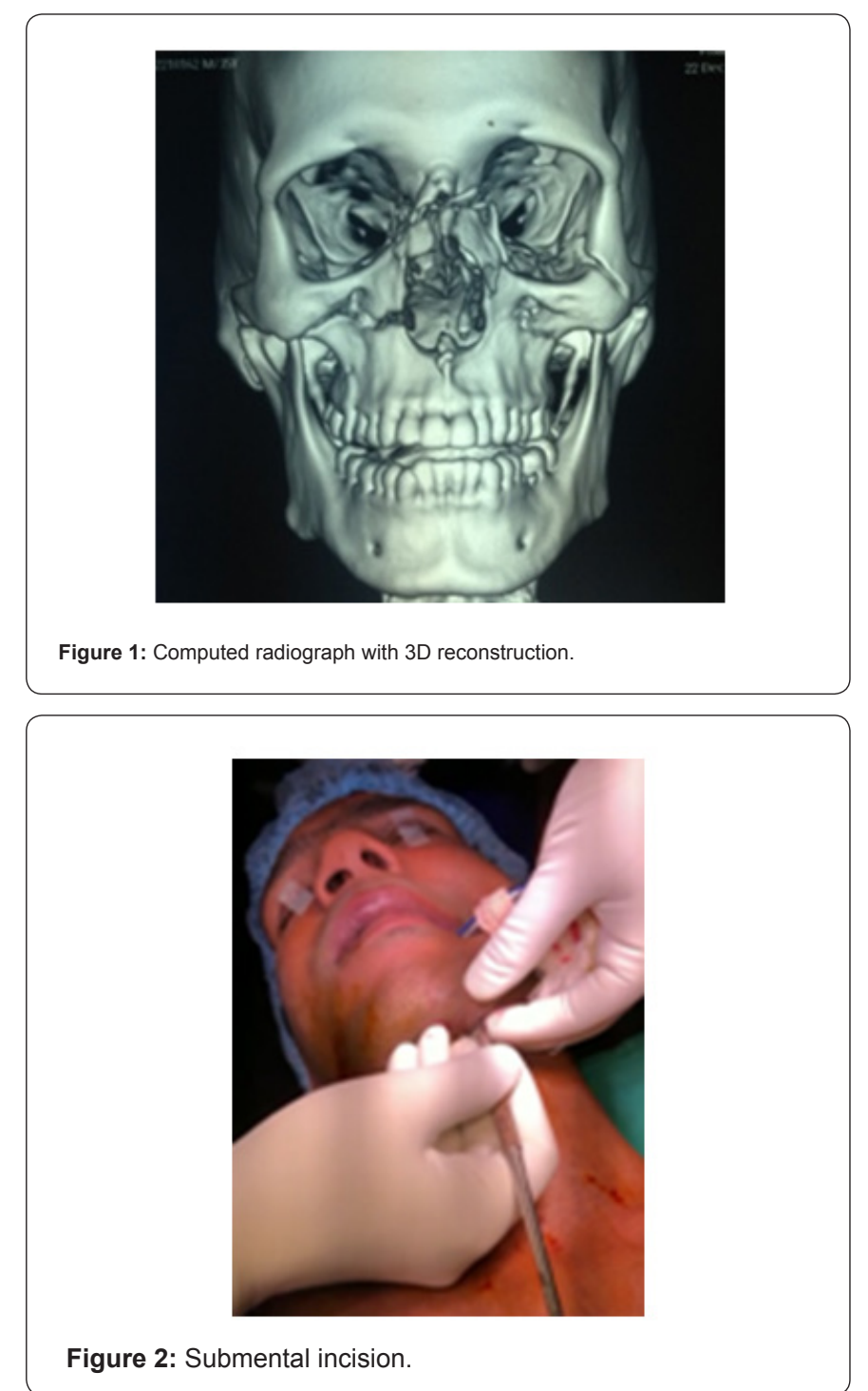

It was extended intraorally through the mylohyoid muscle by blunt dissection. The endotracheal tube was briefly disconnected from the breathing circuit and the tube connector was removed from the tube. The pilot balloon followed by endotracheal tube was gently pulled out through the incision. The tube connector was re-attached and the endotracheal tube reconnected to an aesthesia breathing circuit (Figure 3).

Bilateral air entry was rechecked and found to be equal and the tube was fixed with 1 '0 silk suture. Intraoperatively, the endotracheal tube was away from the surgical field and the surgeons could easily do the intermaxillary fixation to check occlusion. The total duration of surgery was five hours. At the end of surgery, submental intubation was converted to oral intubation. First the pilot balloon and then the endotracheal tube were pulled intraorally. The submental incision was closed using two skin sutures so as to allow certain degree of drainage. Patient was extubated uneventfully. After two months, submental scar was almost invisible.

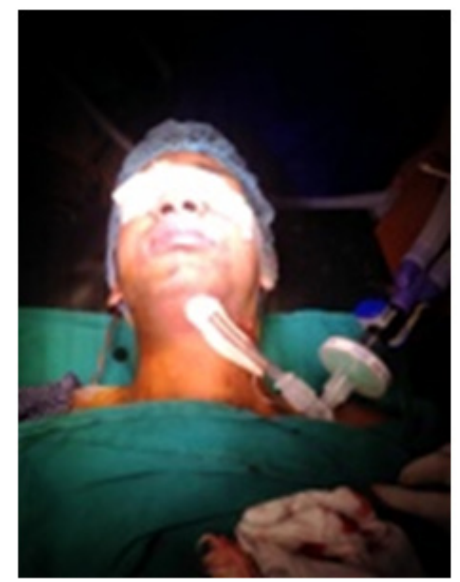

Figure 3: Submental intubation.

\section{Discussion}

Submental intubation is a simple, secure and effective procedure for operative airway control in maxillofacial trauma surgery. It allows surgeons to avoid the risk of epistaxis, iatrogenic meningitis or trauma of the anterior skull base after nasotracheal intubation as well as complications such as tracheal stenosis, injury to cervical vessels or the thyroid gland, subcutaneous emphysema, or recurrent laryngeal nerve injury related to tracheostomy $[3,4]$. The scar from the submental incision is thought to be less visible than a tracheostomy scar and is well tolerated by patients [5].

\section{References}

1. Altemir FH, Montero SH, Montero SH, Montero EH, Peña MM (2004) Hazards of submental tracheal intubation. Anaesthesia 59(11): 1140.

2. Phero JC, Weaver JM, Peskin RM (1993) Anesthesia for maxillofacial/mandibular trauma. In: Benumof JL, (Ed.), Anesthesiology clinics of North America. Anesthesia of otolaryngologic and head and neck surgery. Philadelphia: Saunders, USA, pp.509-523.

3. Caubi AF, Vasconcelos BC, Vasconcellos RJ, de Morais HH, Rocha NS (2008) Submental intubation in oral maxillofacial surgery: review of the literature and analysis of 13 cases. Med Oral Patol Oral Cir Bucal 13(3): 197-200.

4. Amin M, Dill-Russell P, Manisali M, Lee R, Sinton I (2002) Facial fractures and submental tracheal intubation. Anaesthesia 57(12): 1195-1199.

5. Davis C (2004) Submental intubation in complex cranio-maxillofacial trauma. ANZ J Surg 74(5): 379-381. 
This work is licensed under Creative Commons Attribution 4.0 Licens DOI: 10.19080/JHNSS.2018.02.555589

\section{Your next submission with Juniper Publishers will reach you the below assets}

- Quality Editorial service

- Swift Peer Review

- Reprints availability

- E-prints Service

- Manuscript Podcast for convenient understanding

- Global attainment for your research

- Manuscript accessibility in different formats ( Pdf, E-pub, Full Text, Audio)

- Unceasing customer service

Track the below URL for one-step submission https://juniperpublishers.com/online-submission.php 